\title{
Justino de Roma, el primer filósofo católico
}

\author{
Francisco García Bazán \\ INVESTIGADOR DE CONICET
}

\section{El converso Justino de Neapolis. Tentativa de cuadro bio-cronológico}

Justino Mártir, hijo de Prisco y nieto de Braquio, nació en Flavia Neápolis en Samaria, la antigua Siquem y actual Neplusa, próxima al monte Garizim, de familia de colonos instalada allí con el repoblamiento de Vespasiano en el 76. Vio la luz en torno al año 100, como varón gentil y no circuncidado, tuvo una formación filosófica variada que finalmente lo llevó al platonismo y posiblemente formó parte de los grupos de prosélitos o temerosos de Dios, asistentes a las sinagogas locales ${ }^{1}$. Se lo conoce también como Justino de Roma, porque vivió desde alrededor del 138 en la Ciudad Eterna y sufrió allí el martirio en el año 165 o 166. Se lo distingue asimismo como filósofo porque él mismo sostiene que fue su profesión trashumante durante parte de su existencia, aunque posteriormente fijó escuela doméstica en la Urbe. Testigos y discípulos próximos también lo declaran así, como Evelpisto en las Actas de los mártires y Taciano en el Discurso contra los griegos ${ }^{2}$.

De atenerse a dos de sus autorizados informantes, el Patriarca Focio, de mediados del siglo IX, en su Biblioteca, y el historiador y obispo cristiano del siglo IV, Eusebio de Cesarea en su Historia eclesiástica, obtenemos

\footnotetext{
Así se puede deducir de su afirmada gentilidad (Apol. 53, 3-4) y de su buen conocimiento del judaísmo de la época de rica diversidad en las enseñanzas de las sinagogas Ver D. Boyarin, Border Lines. The Partition of Judaeo-Christianity (Philadelphia 2004) 37-73.

2 Ver D. Ruíz Bueno (int., trad. y notas), Actas de los mártires (Madrid 1968) 311-316, «Martirio de San Justino y sus compañeros», y A. Velasco (int., trad. y notas), EuseBIo de Cesarea, Historia Eclesiástica (Madrid 1973), IV, 16, 1-9, I, 233-235.
} 
diferentes informaciones sobre Justino. El compilador bizantino, registra noticias leídas en manuscritos seleccionados y procurando conservar el contenido para la posteridad. Eusebio con intención de construir una historia eclesiástica que es una necesaria historia de la salvación. Escribe Focio de Constantinopla:

«Leída de Justino Mártir una Apología por los cristianos, un libro Contra los paganos y otro Contra los judios, así como también otro tratado Contra el primero y segundo libro de la Física, o sea, contra la forma, contra la materia y contra la privación, libros de argumentaciones ajustadas, vigorosas y aprovechables. Igualmente y del mismo modo, otros Contra el quinto cuerpo y Contra el movimiento eterno que Aristóteles hizo manifiesto mediante la potencia de sus razonamientos, y también sus Soluciones sumarias a las dificultades que se oponen a la religión. $\mathrm{El}$ autor ha alcanzado el ápice en cuanto al conocimiento de nuestra filosofía y de la ajena, desborda de erudición y de riqueza de datos históricos; pero en lo que se refiere a los afeites retóricos carece del afán de adornar la belleza que es connatural a su filosofía [...]. Ha compuesto cuatro tratados contra los paganos. El primero lo ha dedicado a Antonino, llamado el Piadoso, a sus hijos y al Senado, y el segundo a sus sucesores. En el tercero ha discutido sobre la naturaleza de los démones. Su cuarta obra, asimismo compuesta contra los gentiles, tiene por título Refutación. El tratado Sobre la monarquía divina, el denominado Sobre el Salterio y el Contra Marción le pertenecen y son indispensables, igual que él útil Tratado contra todas las herejíasis.

Focio confirma brevemente datos que precisan el cuadro biográfico que diseña, pero, además, aporta observaciones que le dan relieve a otros, como su dominio total de la filosofía, tanto profana como cristiana, y la piedad religiosa. Es decir que para Justino en el verdadero filósofo doctrina racional y vida de piedad constituyen unidad y tratándose de pensamiento cristiano, teoría y práctica religiosa son indisolubles. Asimismo el Patriarca le atribuye que su adhesión a la convicción cristiana de los mártires, es lo que lo llevó a su conversión a Cristo. Lo escrito por Focio es la confirmación de que la figura de Justino seguía siendo para la tradición bizantina de gran significación para la historia del cristianismo y esto debido a la atracción de su identidad filosófica y cultural y de su fervor religioso.

Cuatro menciones especiales dedica Eusebio de Cesarea a Justino. Con la primera emplaza su actividad dentro del cuadro general de la historia de las herejías que él mismo está consolidando con sus referencias a Simón

3 Cf. R. Henry (ed.), Photius, Bibliothèque (Paris 1960) II, 97-98. 
Mago y sus andanzas en Roma enfrentando a Pedro en tiempos de Claudio César -41-54-4 . Después insistirá Eusebio que Justino informaba también que Menandro de Caparatea fue el primer discípulo de Simón mostrando rasgos peculiares de doctrina, lo que deriva tanto de la lectura de la $1 \mathrm{Apo-}$ logía de Justino como de informaciones transmitidas por Ireneo de Lyon, como el mismo lo dice. Y tanto en esta ocasión5 como en la anterior, se pone de relieve el influjo diabólico sobre la conducta de los heresiarcas. En las noticias que prosiguen, empero, Eusebio, trata de proporcionar informaciones cronológicas y personales precisas sobre Justino y su relación con los gnósticos. Cuando se muestran en Roma los cabecillas de la Gnosis, Simón y Menandro, y a partir de este las corrientes de Saturnino y Basílides -uno sirio y el otro egipcio-, durante el tiempo de gobierno del Emperador Adriano, Justino florece contemporáneamente en la misma ciudad. Y ratifica que este oriundo de Palestina habiendo presenciado el coraje de los cristianos cuando el falso mesías Barkokebas los sometía a terribles suplicios en ocasión de la segunda guerra judía (133-135), negándose a renegar de Jesucristo, a pesar de ser calumniados. Comprueba en estos actos la autenticidad y fortaleza de la fe de los judíos cristianos, y toma la decisión de abandonar la filosofía platónica y de convertirse al cristianismo ${ }^{6}$. Sigue el testimonio de la epístola de Adriano con el rescripto sobre las acusaciones contra los cristianos ${ }^{7}$. Concluye finalmente el historiador eclesiástico con el aporte de nuevos datos. Justino ha llegado a Roma iniciado el gobierno de Adriano, pronto estableció escuela y poco antes, otros maestros en relación con el cristianismo y asimismo conocidos: Valentín, Cerdón y el discípulo de este último, Marción del Ponto, se han radicado en le Ciudad Eterna, trasmitiendo enseñanzas que difieren de las de Justino. El alejandrino Valentín y el sirio Cerdón se han radicado en Roma en tiempos del Obispo Higinio, asimismo filósofo (138-142), y durante el siguiente pontificado, el de Pío (142-155), ha florecido Valentín y ha permanecido aquí hasta la época de Aniceto (155-166). Igualmente Marcos de la escuela de Valentín los siguió por aquí. Es también Justino el que como: «Embajador del Logos divino y defensor en sus tratados de la fe en el atuendo de filósofo» (en philosóphou skhémati presbeyon ton theîn lógon kai toîs hypér tês pisteos enagonizómenos syggrámasin) y distinguiendo la diferen-

\footnotetext{
4 H.E. II, 13-14.

5 H.E. III, 25-26.

6 H.E. IV, 8, 3-5: heroicidad de los mártires.

7 IV, 11, 8-11.
} 
cia que existe entre la enseñanza filosófica que trasmite y la de los expositores anteriormente nombrados escribe libros contra los que él mismo señala como herejes, el Contra Marción y el Tratado contra todas las herejías, para el esclarecimiento de los cristianos que residen Roma guiados por los obispos Higinio y Pío. Los comienzos de su estadía en Roma, coinciden, por lo tanto, con el sínodo de presbíteros que expulsan a Marción de la comunidad en julio de 144. Crecida, más tarde, la influencia de su enseñanza en la metrópolis, escribe con sentido de autoafirmación cristiana y de universalidad filosófica, escritos, sin duda, magisterialmente maduros, algunos de los cuales se han conservado. La extensa Apología, dividida en dos partes, redactada en torno al 150, y el célebre Diálogo con Trifón, que también data de esta época, pero que es posterior (157). Eusebio trata de corroborar sus informaciones facilitando breves fragmentos de ambos escritos, los que igualmente había citado Ireneo de Lyon y por los que se puede haber orientado en su exposición ${ }^{8}$.

Llegado el momento, Justino también sufre el martirio con feliz convicción en el año 165, bajo el pontificado de Aniceto, un acontecimiento que no considera infausto y que había incluso previsto que le podía suceder teniendo en cuenta las maquinaciones que contra él urdía su rival, Crescente, filósofo de la escuela cínica, cuya concurrencia lo había alterado y que sintió lastimado su amor propio?.

Pone de relieve Eusebio de Cesarea en su crónica, la firme posición de Justino como baluarte contra las herejías en esta orientación romana que ha encontrado confirmadas en las tesis contenidas en las obras antiheréticas de san Ireneo y de Clemente de Alejandría, aunque no deja a un costado al cronista y polemista judeocristiano Hegesipo (anterior al 110), lo que da a su historia una pincelada de novedad, ya que este escritor proporciona en sus Memorias noticias antiheréticas arcaicas del cristianismo del área palestinense, pero no es tema al que ahora se deba prestar atención ${ }^{10}$.

8 Cf. F. GARcía BAZÁN, «Les origines de la philosophie chrétienne et les gnostiques» en L. Painchaud, P. Poirier (eds.), Colloque Internationel. «L'Évangile selon Thomas et les textes de Nag Hammadi», Québec, 29-31 mai 2003 (Quebec-Lovaina, 2007) 131-155 (especialmente 139-155).

$9 \quad$ H.E. IV , 16, 1-18, 10. Actas de los mártires, ver más arriba n. 2.

10 Eusebio, H.E. IV, 11, 7 y 21; 22, 1ss; asimismo II, 23, 3ss. III, 11; 19; 32, 2ss. y F. García BAZÁN, Jesús el Nazareno y los primeros cristianos. Un enfoque desde la bistoria y la fenomenología de las religiones (Buenos Aires 2006) 282-286. Ver asimismo, «Testimonios y fuentes del 
II. Importancia filosófica de la apología y su proyección en $\mathrm{El}$ diálogo con Trifón.

Ambas obras son las únicas directas conservadas de Justino y subsisten en un solo manuscrito, el Codex Parisinus Graecus 450. Ofrecen un vínculo de estilo inconfundible acerca de su unidad y de sus fines ${ }^{11}$. Con estos escritos, por encima de sus objetivos inmediatos, Justino ha tratado de mostrar la identidad filosófica y religiosa del cristianismo, aunque en diferentes momentos y con interlocutores también diversos, gentiles y judíos, que lo pueden entender ${ }^{12}$. En ambos libros asimismo el autor advierte con constancia que el paisaje de fondo ante el que se levanta la naturaleza típica de la fe cristiana es el piso subyacente que puede llevar a confusión de lo que denomina la herejía. Una denominación que es ante todo un neologismo de carácter filosófico y de tinte peyorativo, una vez que se lo examina críticamente desde la doctrina de la filosofía cristiana. Porque la haíresis, según se la interpreta comúnmente, corriente de opinión justificada en elección de hombres, no tiene su fuente en Dios, es de este modo una opción carente de justificación y así mientras que los fundamentos de las diversas hairéseis de la filosofía helénica o gentil en general, están debilitadas por la ingerencia del factor humano, las hairéseis falsamente llamadas cristianas son perversas y disolutas, están faltas de toda participación en el Verbo de Dios, pues voluntariamente se han alejado de él, constituyendo formas de elección humanamente desviadas, elección que obviamente es solo una muestra y prueba, la más patente, del conflicto de los démones perversos (daimones phaúloı) y de su jefe, Satanás, contra el Verbo de Dios ${ }^{13}$.

Dentro de este marco de múltiples registros se mueve la redacción tanto de la Apología como del Diálogo con Trifón, con diversidad de matices, como se podrá comprobar.

El fin especial en los dos casos es la demarcación de espacios de formas de vida: $1^{\circ}$ los cristianos (khristiánoi) por su doctrina y actividades de adoración, culto y conducta no se pueden identificar con los paganos y

primer filósofo protoortodoxo: Justino Mártir» en J. J. Herrera (ed.), Actas de las V Jornadas de Estudio sobre el Pensamiento Patrístico y Medieval (Tucumán 2010).

11 Ver C. Munier (Int. trad. et comm.), Justin martyr apologie pour les chrétiens (Paris 2006) y Рн. Bobichon (éd. critique, trad., comm.), Dialogue avec Tryphon, 2 vols. (Fribourg 2003).

12 Cf. D. Boyarin, Border Lines. The Partition of Judaeo-Christianity.

13 Sobre el tema ver F. GARCía BAZÁn, Jesus el Nazareno y los primeros cristianos, 263, n. 6 y A. Le Boulluec, La notion d'hérésie dans la littérature grecque IIe.-IIIe. siécles, tome, De Justin à Irénée (Études Augustiniennes; Paris 1985) 36-91. 
ni con los judíos, pero tampoco se debe confundir la naturaleza que le es propia. $2^{\circ}$ Por eso en ambos cotejos los planos significativos cristianos deben mostrar también las credenciales que los autoidentifican. $3^{\circ} \mathrm{Y}$ la mencionada autoidentificación se basa en que exhibe los rasgos de la verdadera filosofía. Porque es ella la que hace posible que culturalmente los cristianos como escuela de filosofía auténtica puedan convivir con las corrientes de la filosofía profana, a la que también se le reconocen valores, en una primera forma de armonía entre la fe y la razón; y al mismo tiempo puedan demostrar ante los judíos que el verdadero Israel superando a la Ley, pero sin romper con ella, es el cristianismo no herético gracias a la inspiración directa del Verbo que lo sostiene. De cualquier manera que se traten de interpretar ambos escritos, se impone la extirpación de la berejía como un tumor maligno endogámico; la separación de lo profano como una expresión religiosa deficiente que puede ser perfeccionada y la necesidad de desenvolver intelectualmente las notas de la sabiduría cristiana como la base y piedra de toque de los otros dos.

El proyecto de autoafirmación frente a la filosofía gentil conjuntamente con la condenación de la herejía se delinea en el plan de la gran Apología cuyo mensaje filosófico circula dentro de las tres grandes partes formales de la petición a la autoridad imperial ${ }^{14}$. Pero Justino a diferencia de Cuadrato (124) y Arístides (141), inaugura una especie de discurso misional que seguirán Anatenágoras y otros: Exordio (A.1-12), exposición (B.1368) y resumen ratificatorio (C. II. 1-15). Las ideas se desarrollan intelectualmente en 21 subdivisiones convencionales que consideramos como unidades temáticas.

A. 1. La Apología está dirigida como una demanda oficial al Emperador Antonino Pío y a sus hijos adoptivos, Marco Aurelio y Lucio Vero, pero debajo del fin jurídico inmediato, se percibe el de la propagación misional, bajo la forma de un protréptico filosófico, se dirige de este modo a filósofos, que buscan o aman la verdad (philaléthe), hombres que prefieren esta a su propia vida y de este modo están dispuestos a ser justos $(1-2)^{15}$.

2. Esta iniciativa se lleva a cabo en un mundo cultural que está impregnado de vida religiosa coronada por la piedad (eusebeía) y la filosofía

\footnotetext{
14 Un biblídion (2Apol. 14,1) o libellus.

15 Ver C. Munier, Justin martyr apologie pour les chrétiens, 12-21.
} 
(philosophía $)^{16}$ y el ideal de gobierno en este ámbito es el del gobernante filósofo (3) ${ }^{17}$.

3. De acuerdo con esto, se puede comenzar la defensa de la causa presentada, admitiendo que no se debe castigar al reo por el nombre, sino por el contenido de la conducta. Acusar a personas por ser «cristianos» (khristiánoi...kategoreímetha) no es justo. Y si el Cristo maestro enseñó a sus discípulos a no negarle y no obstante se le negó y que con esta excusa se hayan levantado las calumnias de los impíos contra todos los cristianos no es honesto, porque no son todos cristianos por el mero nombre, como no todos son filósofos, por el nombre y el atuendo (skêema) (4) ${ }^{18}$.

4. De igual modo fueron los démones perversos los que intervinieron contra Sócrates con la acusación de «ateo e impío» y también contra los cristianos, por el hecho de que algunos fueron ateos. En realidad estos actos anteriores aducidos sucedieron, porque fue el Verbo el que se hizo presente en Sócrates lo mismo que se hizo entre los bárbaros y con mayor visibilidad en el Verbo hecho carne (5).

5. Pero si porque rechazamos a estos dioses que son falsos nos llaman ateos, es admisible, pues creemos en el Dios verdadero en sí mismo y en su Hijo que proviene de él y que nos enseñó todo lo que decimos, en los ángeles buenos que le siguen y en el Espíritu profético, enseñando todo esto como lo que se nos ha transmitido (paradidóntes) también a quien lo quiere aprender «en razón y en verdad» y sin reservas (áphtonos) $(6)^{19}$.

16 Siete veces se reitera el motivo (ver C. Munier, Justin martyr apologie pour les chrétiens, 17). Es evidente que esta introducción excede el carácter de una simple captatio benevolentiae.

17 Cf. Rep. V, 473 d-e. Marco Aurelio solía repetir: Florere civitates, si aut philosophi imperant aut imperatores philosopharentur. Ver AlCino, Didaskálicos 34 (J. WhitTAKeR - P. Louis [eds.] (Paris 1990) 69-71 y nn. y C. Munier, Justin martyr apologie pour les chrétiens, 111-112.

18 Semejante el razonamiento de (7). Pero aquí Justino se apoya en un juego de palabras entre chrestós y christós, basándose en la acepción de khrestós como buen ciudadano, que desea el bien común frente al significado de agitador que ya circulaba (el impulsore Khresto de Suetonio y Tácito). Ver CH. Munier, Justin martyr apologie pour les chrétiens, 113 y A. OrBe, La unción del Verbo (Est. Val. III; Roma 1961), 69-82.

19 Escuela de Cristo. Es la primera vez que se alude a Cristo como maestro, lo que se seguirá repitiendo (ver F. GARCíA BAZÁN, Les origines de la philosophie chrétienne et les gnostiques, 152 y n. 41). Se sostiene que la enseñanza filosófica basada en la tradición cristiana (cf. 1Cor 15) es pública y expresada con claridad y sin mitos, frente a los gnósticos. La referencia a un comportamiento confuso podría aludir a los carpocratianos, estas acusaciones toman aliento civil en el hecho de que los cristianos no pertenezcan a una religio licita. 
6. Ni los cristianos quieren mentir sobre su creencia cuando los interrogan, ni prestar adhesión a la idolatría, sino que consideran que el sacrificio superior para Dios es la virtud, pues siendo bueno crea el mundo de la materia informe y al hombre que no existía otorgándole la incorruptibilidad y convivencia con él, si obra de acuerdo con lo que es divinamente grato $(8,9,10)^{20}$.

7. Esperan los cristianos de este modo un Reino (basileía) que no es humano que se construye por la virtud y al que gobierna el Verbo como Rey. Esta conclusión completa la impiden los démones en el desarrollo temporal y todo esto lo predijo el Maestro. Pero, aunque estemos en situación imperfecta, igual los cristianos con sus conductas que no son reprochables están contribuyendo a la paz del Imperio (11-12) ${ }^{21}$.

$$
* * *
$$

B. 8. La exposición doctrinal propiamente dicha que comienza seguidamente señala, en primer lugar, que es un absurdo tildar de ateos a quienes creen y adoran al hacedor de este universo (demiourgón toûde toû pantós) y a Jesucristo, nuestro Maestro, nacido en Judea y crucificado bajo Poncio Pilato en tiempos de Tiberio César, hijo del mismo verdadero

20 El sacrificio espiritual que tiene en cuenta la ausencia de necesidades en Dios como una corriente de devoción helenística se encuentra asimismo en Filón, Porfirio y los herméticos, y más abajo en 13,1-2. Sobre el sacrificio de naturaleza espiritual ver F. García BAZÁn, «El evangelio de Judas y los démones», Epimeleia. Revista de Estudios sobre la Tradición XVII, 33-34 (2008) 7-34 (especialmente 19-20) y acerca de la creación desde la materia informe con Timeo $30^{\mathrm{a}}$ y sobre la recreación del hombre ver Macabeos II, 7, 28, en F. García BazÁN, «Creatio ex nibilo y Trinidad. Los fundamentos arcaicos de la metafísica cristiana y su actualidad», IV as. Jornadas de Filosofía Medieval (2009), Academia Nacional de Ciencias de Buenos Aires-Centro de Estudios Filosóficos Eugenio Pucciarelli, CD ISBN 978-987-537-072-2-20. El tema de la materia está desvinculado del problema del mal. En 10,3 la felicidad adquiere las notas de la inmortalidad, incorruptibilidad, la impasibilidad y la ausencia de aflicción (ver C. Munier, Justin martyr apologie pour les chrétiens, 135).

Sobre el Reino de Dios - ver particularmente 42,4- es cauteloso Justino, precavido por la rivalidad ante un reino terrestre, prefiriendo orientarse hacia la concepción cristiana de la politeuma con orientación milenarista, y sobre la paz romana, ver $\mathrm{F}$. García BAZÁN, «Designio trinitario y política según los gnósticos», en M. Alesso R. Miranda (eds.), Actas del II Simposio Internacional Helenismo Cristianismo (II SIHC) Universidad Nacional de General. Sarmiento-Universidad Nacional de La Pampa, (1910). Publicación on line ISSN 1853-0621: http://www.sihc.com.ar. 
Dios, y en tercer lugar al Espíritu profético ${ }^{22}$. Los démones, no obstante, ponen obstáculos, pero hemos superado la vida llena de divisiones por una comunidad que no hace acepción de personas y sin disensiones, como lo enseñó Cristo, en: «Discursos breves y compendiosos, pues no era él ningún sofista, sino que su palabra era una potencia de Dios (dýnamis theôu)» (13-14) ${ }^{23}$.

9. Comienzan las citas escriturarias sobre la continencia (encratéia) y la castidad (sophrosýne), la caridad, el trato paciente, no jurar y sólo adorar a Dios, virtudes cristianas que siguen las enseñanzas de Cristo que ocupa el centro de la historia de la humanidad. Son estos seres humanos los que son cristianos, más allá de llevar el nombre ${ }^{24}$ (15 y 16), que pagan los tributos y también aceptan la autoridad del Emperador $(17)^{25}$.

10.La nigromancia, las evocaciones de almas, los simulacros de los sueños (oneiropómpoi) y espíritus asistentes (páredroı) según los magos y fenómenos que se producen por los que saben de esto, confirman que después de la muerte las almas conservan la percepción sensible (aisthesis) y otros hechos que mantienen las enseñanzas de filósofos y poetas, aceptados

22 Creador y datos históricos, contra gnósticos, lo mismo que la cuestión sobre el misterio de la crucifixión. Sobre este punto ver asimismo C. MuNIER, Justin martyr apologie pour les chrétiens, 146.

23 Sobre el Dios trascendente al que sirve de intermediario el Verbo, que no es el Dios cósmico. En este momento es más a Numenio (Fr. 5 a 8, F. García BazÁn, Oráculos Caldeos-Numenio de Apamea [Madrid 1991] 239-242) que a otros autores al que se aproxima Justino. Frases breves, no discursos sofísticos, sino sapienciales -acaso lógoi- y no exposiciones narrativas que es lo propio de los evangelios canónicos en los que se insertan los dichos. Este sería el significado de Memorias (apomnemoneúmata) de los Apóstoles Apol. 67,3, Diál. 105, 1, 5, etcétera. Esto es anterior al género Evangelio. Dýnamis theô̂, ver Filón, F. GARCía BAZÁn, De confusione linguarum, \63, n. 58 y \146-147, n. 117 e Int., en J. P. Martín (ed.), Obras Completas de Filón de Alejandría III (Madrid 2011).

Especialmente Mt, algunas de Lc y una de Mc (y también en EvT, en realidad se trata de una armonización vinculados los dichos kaí, A. Bellinzoni, The Sayings of Jesus in the Writings of Justin Martyr (Leiden 1967). En la moral se acercan más a los judíos helenísticos que a los griegos y romanos: ver Libro 4 de los Macabeos, prólogo y exposición filosófica, 1, 1-3,15.

25 El dicho «Lo del César devolvédselo al César, lo de Dios a Dios» Mc 22, 20-21 no tiene la profundidad de la exégesis gnóstica, que permite deducir su sentido original. Ver Ext. Teod. 86, 1 y artículo citado más arriba en la nota 21. 
también por los cristianos, máxime que los cristianos creen en la recuperación de sus cuerpos, porque la resurrección no es imposible (18-19) ${ }^{26}$.

11.Afinidades paganas por semejanza con lo que se dice del cosmos y su consumación por el fuego por la Sibila, Histaspa, los estoicos y la ordenación y conlusión del mundo según Platón. Respecto de la enseñanza cristiana del Verbo generado y ascendido al Cielo, ella reclama compararse con los relatos sobre Zeus, Asclepio, etcétera y asimismo Hermes: La palabra intérprete y maestro de todos, con otras similitudes con Jesús, no solo como Maestro divino, sino también como Hijo de Dios, lo que también lo indica en afinidad con la caracterización de Hermes, como el Verbo anunciador o mensajero de parte de Dios ${ }^{27}$. Y si Jesús fue sanador, igual Asclepio, y si nacido de una virgen, también Perseo $^{28}$, y si fue crucificado no faltan los dioses hijos de Zeus que también experimentaron sufrimientos letales (20-21-22).

12.Pero lo aprendido por los cristianos del Cristo humanado -Unigénito, primogénito, Verbo y potencia de Dios y guía de los hombres- y los profetas, es más antiguo que lo dicho por todos los escritores griegos y la sola verdad ${ }^{29}$, pero los démones malos antes de su venida influyeron

26 Época de religiosidad matizada, más que difusa. Ver también Diál. 105,4 y E. R. Dodds, Pagan and Christians in an Age of Anxiety (Cambridge 1968) 38ss. La enseñanza es también contra gnósticos. Del semen humano nace el cuerpo, por qué de las semillas humanas esparcidas en tierra no puede nacer la incorrupción-1Cor 15, 53, pero también 2Mac.7, 28ss-. Asimismo Diál. 80,4 y n. 9 (ver BoBichon, Dialogue avec Tryphon, ad loc.). Sensibilidad post motem relacionada con resurrección corporal. Este tipo de sobrevida no rompe el vínculo con el cuerpo que espera la transformación estable. Si se salva adquiere los rasgos de la felicidad eterna (n. 20), si se condena sufre igualmente indefinidamente. Ver Munier pp. 167 y 170-171. J. PéPIN, Theologie cosmiqueet théologie chrétienne (Paris 1964) 443-466.

27 Parece ser el Hermes heleno combinado con el egipcio según lo practicó el neoestoico A. Ornuto al basarse sobre la universalidad del Logos (cf. I. Ramelli (ed.), Theologiae graecae compendium, (Milán 2003) 207-215. Ver también Tim 28c, 30ª y 69b.

28 Tema también prognóstico por el uso de diá para la virginidad de María y no ek o apó. Ver Ireneo de Lyón, Adv. Haer. I, 7,2 y III, 11,3 (M. TARdieu, «Comme à travers un tuyau», en R. BARC (ed.), Colloque International sur les Textes de Nag Hammadi. Québec 1978 (Quebec-Lovaina 1981) 151-177, asimismo el Testimonio de la Verdad (NHC IX, 3) 40, 1-10, en A. Piñero - J. Montserrat - F. García BazÁn (eds.), Textos gnósticos. Biblioteca de Nag Hammadi III (Madrid 2000) 223-224 y n. 10.

29 Preexistencia, antigüedad y Verdad. Aristóbulo, Eupolemo, Artapano. Ver A. J. DroGE, Homer or Moses? (Tubinga 1989) 12-35 y F. GARCía BAzÁn, La religión hermética. Formación e historia de un culto de misterios egipcio (Buenos Aires 2009) 88-89, n. 5. 
con mitos y leyendas poéticas y prosiguen con obras impías contra nosotros. Tres pruebas lo demuestran: a) decimos discursos semejantes a los griegos, pero se nos odia por llevar el nombre de Cristo; b) porque antes como no conversos dábamos culto a los dioses paganos, pero ahora siendo cristianos, la consagración total es al Dios inengendrado y libre de pasiones. c) Porque los herejes no son perseguidos, sino hasta honrados como dioses. Sin embargo, son llamados impropiamente cristianos aplicándose a ellos la falsa analogía de los diversos filósofos como miembros de la filosofía usando una concepción de la filosofía perimida por ser autocontradictoria (23-24-25-26) ${ }^{30}$.

13.Confirmación progresiva de la superioridad de la doctrina cristiana aplicada a la ética social en tres dominios: frente a las calumnias de relaciones incestuosas, rechazo de la exposición de los recién nacidos y de la explotación de rebaños de niños, afeminados, andróginos y pervertidos para realizar uniones promiscuas y de la mutilación ritual para sacar ganancias materiales. Condena asimismo del culto de la serpiente: «Porque entre nosotros el príncipe de los malos démones se llama Serpiente, Satanás, Diablo y Calumniadon ${ }^{31}$, y si Dios no lo castigó a Satanás y su ejército definitivamente, es porque prevé que algunos todavía se arrepentirán. Porque al principio Dios creo al género humano intelectivo (noerón), o sea, capaz de distinguir entre la verdad y el obrar bien y lo que no es bueno, un ser razonable (logistikón) y contemplativo (theoretikón). Se quiere evitar el posible homicidio del niño expósito (27,

30 Desde 23 hasta 60, está incluida toda la doctrina cristiana y cristológica. Viene como prueba en 26 la noticia plenamente antignóstica sobre Simón, y Menandro -una corriente que directamente Justino ha conocido en Samaria e incluso el detalle del endiosamiento simoniano (ver asimismo Diál. 120, 6: «La prueba es que sin preocuparme de nadie de mis paisanos, quiero decir, de los samaritanos, he comunicado por escrito al Emperador que están engañados siguiendo al mago Simón, de su propio pueblo, que afirman ellos ser Dios por encima de todo principio, potestad y potencia»), por más que el Simoni Deo Sanco sea una confusión con la divinidad sabina Semone Sanco deo que presidia los pactos y que el provocador social Marción -cuyos ecos en Roma se debían conservar vivos al ser excluido de la comunidad en el 144- y el llamado de atención de la mención de la redacción más amplia del Syntagma katá pasôn tôn gegenoménon hairéseon.

31 Para los dos primeros casos ver R. STARK, La expansión del cristianismo. Un estudio sociológico (Madrid 2009). Ver asimismo el culto pagano de la serpiente como divinidad ctónica (Munier, 187-191), pero sobre todo contra ofitas Diál. 103, 5 con su etimología samaritana. 
28, 29). El casamiento tiene el solo fin de la procreación de hijos y si renunciamos al matrimonio somos totalmente castos ${ }^{32}$.

14.Desde los parágrafos 30 a 42 se disertará sobre la profecía como la máxima prueba de la enseñanza cristiana. La palabra profética de los judíos (Moisés, los Salmos, Isaías, Zacarías) han predicho los acontecimientos por venir y los reyes las observaron y consignaron en libros en lengua hebrea ${ }^{33}$ y de aquí fueron traducidas al griego en Egipto y se esparcieron por todo el mundo. Los judíos no entienden el contenido profético que encierran y odian y persiguen a los cristianos. La conducta cruel de Barkokebas lo confirmó. Así están consignadas anticipadamente las profecías sobre Jesús, «el maestro nuestro e intérprete de las profecías desconocidas (agnoouménon)», que cerró el linaje real auténtico de Israel y al que todos los pueblos esperan nuevamente, que entró triunfalmente en Jerusalén, fue concebido por una virgen no por comercio carnal, sino por la Potencia de Dios que la cubrió con su sombra (Lc. 1), que nació en Belén, que vivió oculto hasta la edad viril, que los judíos lo desconocieron como el Mesías, que fue crucificado ${ }^{34}$ y que resucitó. Todo esto resulta ser así porque a través de los profetas habla el Espíritu profético, el Espíritu santo divino profético ${ }^{35}$. Igualmente fue también profetizado sobre los $D_{o c e^{36}}$, que salieron de Jerusalén y convencieron a todo el mundo -indoctos y faltos de elocuencia

32 Al punto de que alguno en Alejandría para contrarrestar la acusación de la unión promiscua como un misterio celebrado por nosotros los cristianos, quiso mutilarse los testículos, pero no se le permitió y quedó célibe. A diferencia con Justino en relación con la procreación como el fin único del matrimonio ver J. CRisóstomo, Propter fornicationes: «Porque hay dos razones por las que el matrimonio haya sido introducido: para que podamos ser moderados y para que seamos padres. Sobre estas dos razones el motivo de la moderación es primario...», en Jesús el Nazareno, 205.

33 Igual el profeta Petosiris instruye al rey Nechepso en Egipto.

34 Certificación por las Actas de Pilato, 35, 9. Justino con Mt 1, 23 y la Septuagisnta (Is 7,14) retiene el término parthénos (virgen), frente al 'almâ/neânis (muchacha soltera o casada) de la masorética, seguido por Símaco, Aquila y Teodoción.

35 to prophetikón pneûma., to theión ágion prophetikon pneûma, es decir, el Espíritu de Dios en su función predictiva en el A.T. y también en Cristo, que los que creen en él la entienden, porque en ellos como en los mismos profetas mora la semilla proveniente de Dios, que es el Verbo, primogénito y Salvador [ = nombre Jesús], que es quien prorrumpe o habla por la inspiración.

36 Salmo 18, 3-6. 
(idiótai- laleîn me dynámenoi) - por la potencia de $\operatorname{Dios}^{37}$, y sobre el reino de Cristo con su ascenso al cielo y alegría (euphrosýne) de cuantos esperan la inmortalidad.

15.Lo dicho sobre la profecía no significa que el hombre sea esclavo del destino (beimarméne), pues actúa usando el libre albedrío (epi bemin-autexô̂sion) y la decisión deliberativa (proáiresis) y de este modo sus actos son buenos o malos, porque durante su existencia pasa de un contrario a otro, ya que es agente de elección. Lo que la profecía anticipa no hace al hombre víctima de la necesidad del destino, sino que el preconocimiento o providencia divina (prónoia) es propia de Dios y por su adhesión voluntaria a ella el hombre es recompensado. El Espíritu profético expresa este diseño divino interior y ayuda al hombre a cumplir la Voluntad divina. En este sentido la expresión de Platón: «La culpa es de quien elige, Dios no tiene culpa» es correcta, porque los gérmenes de Verdad están por doquier, pero los griegos, también cuando hablan de la inmortalidad del alma y de la contemplación de las entidades celestes, han tomado la instrucción de Moisés, el profeta más antiguo, y los profetas ${ }^{38}$ y los démones lo frenan. Incluso la prohibición de leer a Histaspa y la Sibila es obra de ellos (43-44).

16.Igualmente fue anticipada la Ascensión gloriosa de Cristo al cielo después de su resurrección y retenerle hasta concluir con los demonios y completar el número de los reconocidos como buenos, para después cumplir con la conflagración universal. Porque también se anticipó con Vara de Poder, «el anuncio de la palabra poderosa, que saliendo de Jerusalén, predicaron por doquiera sus apóstoles, y que nosotros, a despecho de la muerte decretada contra los que enseñan o que en absoluto confiesan el nombre de Cristo» (bólos homologoúnton to ónoma tôे Khristo $\hat{l}^{39}$, la abrazamos y enseñamos. Y quienes vivieron conforme al Verbo son cristianos antes de Cristo ${ }^{40}$. También el Espíritu profético

37 Ellos podrían haber dicho con Eurípides: «La lengua juró, pero el alma no ha jurado», pero esto sería ridículo. Rasgo antignóstico, ver GARCíA BAZÁN, «Les origines de la philosophie chrétienne...», 153 y n. 43 y ahora Munier, 217.

38 Subyace la crítica al estoicismo de Crisipo, ver también Alcino, Didaskálicos 26 [J. Dillon, The Middle-Platonists. A Study of Platonism 80 B.C. to A.D. 220 (Londres 1977) 209ss.]. Moisés el profeta más antiguo, para menciones similares de Aristóbulo, Artapano, ver n. 29 más arriba.

39 Contra gnósticos que no confiesan el nombre, igual que antes en n. 37.

40 Sócrates, Heráclito, Abrahán, Ananías, Azararías, Misael y otros. 
predijo la devastación de la tierra de los judíos ${ }^{41}$ y los milagros de Cristo ${ }^{42}$ y la adoración de la gentilidad ${ }^{43}$, y los sufrimientos de la pasión y la gloria de Cristo ${ }^{44}$ (45-51).

17.Pero si se predijo la subida al cielo, también se profetizó su posterior venida con gloria, según Daniel $(7,13)$, o sea, no solo lo sucedido, sino también lo que ha de suceder. Por eso son dos los advenimientos de Cristo, el segundo con gloria y acompañamiento de ángeles y la resurrección de todos los muertos, unos con incorruptibilidad los otros, con los demonios, para el fuego eterno. También la cruz se ha remedado anticipatoriamente (52-55).

18.Pero los démones malvados no descansan y además de sus fábulas han suscitado personajes como Simón y Menandro ${ }^{45}$ (56-57-58).

19.Del Verbo que habló por los profetas tomó también Platón que Dios hizo el mundo de una materia informe, porque de Moisés, muy anterior a los griegos, se valió el Espíritu profético cuando se expresó en Gn 1,1-3, ya que por la Palabra de Dios hizo el mundo de elementos preexistentes. También el poeta que habla del Erebo lo tomó de él. Y la forma de X en el Timeo que le dio el Hijo de Dios para formar el mundo también la tomo de Moisés porque en el desierto al darle forma de cruz al bronce liberó de las serpientes y al hablar Platón de tres seres que se siguen ${ }^{46}$ y lo mismo lo de la conflagración universal (59-60).

20.Seguidamente se exponen los rituales cristianos y su sentido regenerativo $^{47}$. Primero el rito de ingreso y las condiciones requeridas: lugar de agua; después el significado y el poder que transforma, en el Nombre

41 Is. 64,10 y 7,1 .

42 Is. 35, 5. Esto también se registra en las Actas de Pilatos.

43 Is $65,1-3$, ampliado en $\$ 54$.

44 Is 52,13 ss.

45 Noticia dada anteriormente (26) y referencia a Marción del Ponto, antes también mencionado, pero ahora con una breve noticia, aunque más amplia. Estas reiteraciones como posteriormente en el Diálogo se registran solo para los gnósticos.

46 Carta II 312e, también registrada en Valentín y en el Himno de los naasenos de Hipólito. Aquí ha tomado Justino varias reiteraciones de naturaleza técnicamente filosófica que contrasta con la verdad plena de la filosofía cristiana. Ver más arriba n. 30.

47 Los ritos que no son ajenos a los usos romanos, por eso se extienden las explicaciones que quieren evitar confusiones. 
del Padre ${ }^{48}$, del Hijo que muestra su efectividad como Verbo recreativo, y del Espíritu que todo lo anunció por los profetas. El aspecto de la purificación del baño lo anunció Isaías 1, 16-20, pero el regenerativo, Jn. 3, 3-44. De los Apóstoles aprendimos que puesto que nuestro primer nacimiento no fue consciente -al haber sido obra de la necesidad de un germen húmedo, o sea, de la naturaleza- y nos criamos en costumbres viciosas, ahora somos hijos de la libre decisión (proaíresis) y de la ciencia (episteme), esto por obra trinitaria -en donde el Verbo se hace presente por su efectividad-y así el rito se llama iluminación (photismós), porque fuimos iluminados en este baño ${ }^{50}$. Los demonios quisieron importunar este lavatorio, pero su eficacia se anunciaba ya en Moisés, por eso el acto de descalzarse y el llamado desde la zarza del Dios sin nombre (anonómaston), de la colaboración de su único vástago, mensajero y enviado (ággelos kai apóstolos) (Mt 11, 27), el Verbo, que es el que habla en la zarza: «Yo soy el que es, el Dios de Abrahán, Isaac y Jacob». Y fueron también los demonios los que para tergiversar el sacramento pusieron a Core en las fuentes de agua y Atenea salida de la cabeza de Zeus como primer pensamiento (próten énnoiam), lo que es ridículo, poner a una mujer como imagen del pensamiento (tes énnoias eikóna $)^{51}$. Después del lavado y adhesión, al ingresante lo llevamos ante los hermanos y si antes del bautismo hubo ayunos, ahora hay oraciones, un ósculo de paz, al que preside se le proporciona pan y un vaso de agua y vino y se tributan alabanzas al Padre del universo a su Hijo y al Espíritu Santo, concluyendo las oraciones con la acción de gracias, y los diáconos dan a los asistentes parte de las tres especies. Este alimento es la Eucaristía., como ofrenda de la carne y sangre del Jesús encarnado. Así está en los Recuerdos de los Apóstoles: «Haced esto en memoria mía, esto es mi cuerpo» ${ }^{52}$ (61-68).

48 Que es impronunciable, lo que Moisés expuso en Ex 3, 14.

49 Que no se puede entender como volver al seno (adýnaton) materno. Es una acotación antignóstica.

50 También es aclaración antignóstica, contra los misterios, por eso en Diálogo 35 se reitera y expresa la condena sin explicaciones mayores.

51 En polémica antignóstica, porque ya en las noticias sobre Simón se hablaba de la Ennóia de Dios salida de su cabeza (Helena), que lo acompañaba. Ver asimismo Ireneo, $A d v$. Haer. I, 23, 1-4, Homilías Pseudoclementinas II, 22-25 y Reconocimientos II,ss. (F. GARCíA BAZÁN, La gnosis eterna. Antología de textos gnósticos griegos, latinos y coptos (Madrid 2003) 58-64).

52 O sea, los relatos transmitidos y conservados. También el día del sol se celebra una reunión de todos (porque se pasó de la tiniebla a la luz y fue la resurrección) y se leen 
C. 21. La parte final del escrito que exponemos que aparece como 2Apología se apoya en un proceso de acusación presentada al prefecto Lollio Urbico contra una mujer y la sucesiva condena del didáscalos Ptolomeo, de Lucio y de un tercero por no renegar del nombre de cristianos. Se ratifica con esto como los démones han ampliado su odio anticristiano (1-2). Se confirma la negación cristiana del suicidio, pues Dios crea el universo provisto de un orden total, pero los ángeles se rebelan contra ese orden y enamorándose de las mujeres engendran hijos que son los demonios. Así hicieron esclavos a los hombres de la magia, de los mitos demás perversiones (3-4 ${ }^{53}$. Se amplia con Apol. 33, 7-8, y otros lugares previos, que Dios, Padre del universo, carece de nombre impuesto por otro, porque ninguno ha existido para eso. Los nombres padre, Dios y otros son denominaciones (prospréseis) (5). De nuevo también la visión estoica de la conflagración universal y el destino (heimarméne) ratifican el rechazo, porque se espera completar todas las semillas (6). Reiterado acercamiento a las semillas del Verbo ingénitas en todos y en algunos manifestadas de antemano pese a los démones (Heráclito, Musonio, los profetas) y el Verbo total (7). Hay un paréntesis de teología histórica con el presentimiento del martirio por parte del autor por la acusación y odio de Crescente que ignora al cristianismo y actúa como agente de los démones, los que antes actuaron también sobre Sócrates acusado como ateo e impio. Incluso los démones malos establecen las leyes perversas de las naciones, pero hay una justicia eterna (8-9). La religión cristiana aparece como la más sublime porque el Verbo entero se hizo cuerpo, discurso racional y alma, y cuanto se ha dicho de bueno es mirando al Verbo total, pero eran expresiones filosóficas parciales y por eso se contradijeron. Sócrates, valiéndose de la investigación de la razón conoció en parte a Cristo y le precedió, igual que otros filósofos, hombres cultos y artistas, porque Cristo es «la potencia del Padre inefable» (es decir, el instrumento de la actividad paterna) (10). En el relato de Heracles ante el cruce de caminos este debe optar entre la benevolencia del vicio o el rigor de la virtud. Elige

los Recuerdos o los profetas, y hay una exhortación sobre ellos. Después oraciones, después consagración de pan, vino y agua, distribución a la comunidad y ayuda a los necesitados, y todo se repite. Similitudes y diferencias con el gnosticismo. La coloración litúrgica ya estaba en 65, 1, 66, 2 y 67, 1-2.

53 Gén 6,1 ss. con la condena de la magia y la tecnología como su instrumento, no contra la ciencia. El mismo tema se prosigue más abajo en relación con la ambigüedad de la palabra proferida. 
la virtud. Es la elección que hacen los cristianos. Por eso cuando los vio ir intrépidamente a la muerte (motivo recurrente, pero con el rasgo del testimonio personal en este momento) y dejó el ser platónico por la divina filosofía (philosophia theía), fue por el convencimiento de que se ha elegido lo permanente (el camino de la virtud), frente a lo cambiante y efímero (el placer y el vicio, como hizo Hércules en el cuento de Jenofonte. (11-12). Afirma de este modo Justino en el cierre del escrito: «Soy cristiano», desde que descubrí que los démones malvados ponían un velo a las enseñanzas cristianas y también que antes de Cristo hubo los que hablaron bien por afinidad. Están en el tiempo, las semillas del Verbo, el Verbo y los que siguen la enseñanza del Verbo. Lo que participa y lo que concede la participación: «Una cosa es, en efecto, la semilla y la imitación de lo que se da conforme a su capacidad, y otra aquello mismo a partir de lo que se genera la participación e imitación conforme con la gracia que también de él procede ${ }^{54}$. De este modo asume el autor su responsabilidad plena, «quiero que se conozcan públicamente la Verdad según estas doctrinas la muestran» (13-14-15).

En resumen la filosofía cristiana de Justino es al mismo tiempo metafísica, cosmológica, histórica, antropológica, ética y gnoseológico-epistemológica in nuce.

El Dios inefable convive internamente con el Hijo-Logos y el Espíritu Santo inspirador. El Logos/Palabra está junto al Padre y como su Potencia verbal crea, el mundo y su orden ontológico y racional, que es así manifestación de la providencia paterna. Este designio oculto se torna plena revelación en la encarnación concreta en la historia -tiempo y espacio-. Hacia este arquetipo y su proyección hacia el futuro tienden todas las semillas (spérmata) o imitaciones (mimémata) sembradas por el mismo Logos, que no crecen espontáneamente como los vástagos de naturaleza, por dos razones, primero porque la criatura se manifiesta como «animal viviente libre y apasionado» y segundo porque bajo esta manifestación subyace una constitución triple de cuerpo, razón y alma, y su libertad y razón intelectiva le hacen que tanto acierte como se equivoque. De este modo, su participación en la potencia del Logos se torna impotente y los démones contrapotentes están al acecho, procurando que el designio

$54 \quad 13$ al final, es la doctrina filosófica de la potencia según la capacidad del receptor y la del dador. 
divino sea una gestación difícil y si es posible sin alumbramiento. La caída de los ángeles y en especial de Satanás protagoniza la contrapotencia opositora mencionada, que impide que el compuesto humano alcance la salvación en todos los casos y el juego entre la oposición demónica y la necesidad de que todas las semillas del Logos tengan su oportunidad, ordena la organización progresiva de la historia y del cosmos. De este modo, ni la conclusión del mundo es inmediata, ni el suicidio es permitido y los exorcismos son efectivos en la trama providencial.

\section{Las confirmaciones del Diálogo con Trifón}

El Diálogo con Trifón viene a repetir, confirmar con diferente tratamiento o ampliar con nuevos elementos esta doctrina filosófica y ahora teniendo a los judíos como destinatarios de la mostración de la propia identidad. El largo escrito tiene una estructura en apariencia desordenada unida por extensas citas de las Escrituras. Sin embargo, hay en él una ordenación interna en la que las postergaciones de las preguntas y las digresiones solo en apariencia rompen la unidad de la composición, porque son recursos que vienen en apoyo del fortalecimiento de las respuestas y al desorden de la redacción sirven de fondo inquietudes que provienen del Sýntagma cuyo contenido nos es desconocido directamente, y las soluciones doctrinales de la Apología ${ }^{55}$. Es de nuevo la exposición de doctrina filosófica la que guía el diálogo que refuerza la enseñanza del Cristo en relación con la salvación como el fin último del hombre, el fundamento de la felicidad (eudaimonía) y la que ocupa el lugar central en la filosofía de la historia, por eso la introducción a la obra temáticamente filosófica no es separable del conjunto, sino la bisagra que une la Apología con el Diálogo, lo organiza y le otorga el sentido de la transmisión de una verdad universal y única ${ }^{56}$.

55 Cf. P. PRigent, Justin et l'Ancien Testament. L'argumentation scripturaire du traité de Justin contre toutes les hérésies comme source principal du "Dialogue avec Tryphon et de la «Première Apologie» (Paris 1964); Bobichon, Dialogue avec Tryphon, 153ss.

56 Ver Bobichon, Dialogue avec Tryphon, 149-152. En efecto, desde el parágrafo 1 al. 8.2 hay una combinación de autobiografía intelectual y de enseñanza que es crucial como vínculo y proyección sobre el resto de la obra. De este modo inicia el autor el Diálogo con el exordio filosófico y lo prolonga dando entrada al coloquio. Si en la Apología el pensamiento gnóstico es rechazado ante la verdadera filosofía, en esta presentación propedéutica, se exaltan los milagros de los profetas que glorifican al Dios creador, anunciando a Cristo que de él procede y se concluye con las palabras a Trifón: «Ahora bien, si tú también te preocupas algo de ti mismo y tienes confianza en Dios, como a hombre que no es ajeno a estas cosas, posible te es alcanzar la felicidad, reconociendo al Cris- 
I. De 1 a 8,2 se describe un breve itinerario filosófico en el que se descartan como escuelas de paso aptas para la formación a la epicúrea, la estoica, la peripatética y la escéptica ${ }^{57}$ y se incluyen como aptas para el fin de la búsqueda de Dios, la pitagórica y la platónica. La primera se descuenta con precaución, puesto que el aprendizaje previo de los cuatro grandes saberes (aritmética, geometría, armonía y astronomía) ${ }^{58}$, pone obstáculos para el ingreso directo en la dialéctica inteligible, ya que desde el ejercicio de ésta sería posible la posterior visión de Dios. Esta exigencia significa para Justino una pérdida de tiempo innecesaria y la enseñanza de los platónicos se le ofrece como más efectiva para alcanzar a Dios, aunque insuficiente. De qué tipo de platonismo se trata siendo al menos cuatro las corrientes que en ese tiempo se comprueban como seguidas por platónicos: los platónicos que pitagorizan, subdivididos en los fieles a la rama platónica de Espeusipo o a la dualista insinuada por Jenócrates, los platónicos académicos o los platónicos medios propiamente dichos como Alcino, Plutarco, Atico o el comentarista anónimo del Teeteto, no es fácil decidirlo, porque si por el vocabulario filosófico Justino parece provenir de estos últimos, por las dos definiciones de filosofía que proporciona parece ser familiar con platónicos pitagorizantes e incluso con Numenio, el pitagórico ${ }^{59}$. Por otra parte, cuando Justino se encuentra con el anciano interlocutor (palaiós tis presbýtes) y entra en contacto con la divina filosofía el enfoque filosófico descriptivo da un giro y el tema en el que se concentra la reflexión para avanzar es la antropología, desde cuyas bases es posible descartar un enfoque de tendencia cosmológica, porque gracias al esbozo antropológico que se ofrece se hace posible conocer a Dios y alcanzar la salvación por el logro de la inmortalidad. Efectivamente, el alma como principio de vida del cuerpo no posee la vida por sí misma. Su vida proviene del espíritu viviente que Dios le otorga como criatura y que se lo puede arrebatar. Cuando el alma se separa del cuerpo el hombre muere, pero porque Dios lo quiere el hombre resucita gracias a que su alma está dotada de espíritu de vida. De este modo Justino ratifica la constitución humana de cria-

to de Dios e iniciándote en sus misterio (epignónti soì ton Khiston toû Theoû keai teleí genoméno)». Las carcajadas son la respuesta, ante quien trata de iniciarse en serio.

57 O sea, teórica o escéptico pirrónica.

58 La enumeración es un poco descuidada, ver F. GARCíA BAZÁN, «Les origines de la philosophie chretienne» 145.

59 Cf. J. Opsomer, In Search of the Truth. Academic Tendencies in Middle Platonism (Bruselas 1998) 265-269 y F. García BAzÁn, Plotino sobre la trascendencia divina: sentido y origen (Mendoza 1990), Cap. IV y F. García BAZÁn, «Antecedentes, continuidad y proyecciones del neoplatonismo», Anuario Filosófico 33 (2000), 111-149 (esp.116-118). 
tura que había enseñado como poseedora de cuerpo, razón y alma, de alma racional con función tanto lógica (logikós) como intelectiva (noerós) ${ }^{60}$, capaz de conocimiento superior y de participación responsable en el designio del Verbo. Paralelamente puede eliminar el razonamiento del autor la necesidad del alma del mundo de los platónicos y pitagóricos que le da permanencia eterna a este como gran animal viviente y también por participación en ella a los vivientes particulares, descartando el riesgo de la metempsomatosis. Por otro lado, con esta concepción de la psiquis puede disolver la relevancia del espíritu (pneûma) como capaz de autoaislamiento incorpóreo o liberación espiritual propio de los gnósticos. El Verbo como Cristo Salvador y Maestro se levanta en el centro de la historia y es el eje de la concepción de la filosofía de la historia justiniana frente a griegos y judíos.

II. Por ese motivo en el parágrafo 35 del presente escrito es posible acentuar con nuevos trazos sobre la berejía lo que se anticipó como una desviación profunda del designio divino en la Apología:

«Hay, pues, amigos, y los ha habido, muchos que han enseñado doctrinas y moral atea y blasfema, no obstante presentarse en nombre de Jesús, y son por nosotros llamados del nombre de quien dio origen a cada doctrina y opinión. Y, efectivamente, unos de un modo y otros de otro, enseñan a blasfemar del Hacedor del universo y del Cristo que por Él fue profetizado que había de venir, lo mismo que del Dios de Abrahán, Isaac y Jacob. Nosotros no tenemos comunión ninguna con ellos, pues sabemos que son ateos, impíos, injustos e inicuos, y que, en lugar de dar culto a Jesús, solo de nombre le confiesan. Y se llaman a sí mismos cristianos, a la manera como los gentiles atribuyen el nombre de Dios a obras de sus manos, y toman parte en inicuas y sacrílegas iniciaciones (anómois kai athéois teletaîs). De ellos unos se llaman marcionitas, otros valentinianos, otros basilidianos, otros saturnilianos y otros por otros nombres, llevando cada uno el nombre del fundador de la secta (gnómes), al modo como los que pretenden profesar una filosofía, como al principio advertí, creen deber suyo llevar el nombre del padre de la doctrina que su filosofía profesa» ${ }^{61}$.

60 Alcino ha aplicado el adjetivo al Dios noético, al alma del mundo y al mundo. Esta definición por la constitución está oculta en la observable, viviente racional libre y pasible.

61 Ver 35, 4-6. De 56 a 60 se proporciona una interpretación que afirma al Dios trascendente y a su Verbo como el «Dios de Abrahán, de Isaac y de Jacob» en la historia de los Patriarcas, teofanías sucesivas que no permiten separar en un Dios desconocido y un dios creador inferior como sostienen los gnósticos. Ver Bobichon, Dialogue avec Tryphon, II, 679, n.15, igualmente 732-744. 
Justino como filósofo profesional de origen medioplatónico entiende la filosofía primariamente como búsqueda o amor a la verdad y como filósofo cristiano ha tenido la oportunidad de descubrir la plenitud de la investigación, o sea, adhiere a la Verdad misma encarnada, al Logos universal y único, Jesucristo.

Los gnósticos tomando por ejemplo de reflexión crítica la filosofía de los platónicos que pitagorizan entienden la filosofía como conocimiento de lo que realmente es y como filósofos cristianos que conocen, como gnosis que salva, experiencia cuyo logro restaura en su plenitud el reino de los seres pneumáticos. Para los gnósticos la filosofía cristiana es conocimiento salvífico y misterio iniciático conjunto. Por eso condena Justino: «Y toman parte en inicuas y sacrílegas iniciaciones», lo que se refuerza con sus reproches sobre los misterios paganos según se comprueba en la Apología, pero que es una terminología que también encierra un sentido positivamente cristiano: la iniciación en los misterios de Cristo ${ }^{62}$.

III. Es igualmente posible entender el desvío de las herejías cristianas, pero también el significado de las llamadas por los judíos herejías judías, prefiguraciones de las cristianas por el impulso desmembrador de los démones y en esto lo que se confirma es la concepción personal de Justino como autor que se mueve en el mundo grecorromano, frente a otros autores antiheréticos, como Hegesipo, que, sin embargo, ha actuado en el medio judeocristiano palestinense:

«Porque los que se llaman cristianos, pero son realmente herejes sin Dios (athéous) y sin piedad (asebeîs), ya te he dicho que solo enseñan blasfemias, impiedades e insensateces... Y si vosotros habéis tropezado con algunos que se llaman cristianos y no confiesan eso, sino que se atreven a blasfemar del Dios de Abrahán y de Isaac y de Jacob, y dicen que no hay resurrección de los muertos, sino que en el momento de morir son sus almas recibidas en el cielo, no los tengáis por cristianos; como si se examina bien la cosa, nadie tendrá por judíos a los saduceos y sectas semejantes de los genistas, meristas, galileos, helenianos, fariseos y baptistas..., sino por gentes que se llaman judíos e hijos de Abrahán, pero que solo honran a Dios con los labios.... ${ }^{63}$.

62 Ver Diál. 8,2 y más arriba n. 56.

63 80, 3-4. Pero aquí uno es el tema del rechazo del Dios del A.T. (idea marcionita y gnóstica) y otro el tema más genérico de la resurrección (ver BoBichon, Dialogue avec Tryphon, 787). Dice E. DE CESAREA con referencia a Hegesipo: «El mismo autor 
Para Hegesipo, no obstante distinguiéndose de Justino, se trata de diferentes corrientes de opinión dentro del pueblo que no rompían la unidad, aunque iban contra creencias de la tribu de Judá (en la que nacería el Mesías de David) y el Cristo.

IV. Pero la función insoslayable que desempeñan los démones/demonios en la historia de la salvación según lo hemos señalado en la Apología estando ahora Justino desarrollando su autoidentificación ante los judíos le hace detenerse en el origen mismo del jefe de los demonios y obviamente lo hace mostrando su perfil originario en el marco de las corrientes gnósticas arcaicas, los naasenos u ofitas ${ }^{64}$, que parece conocer de oídas por

describe además incluso las sectas que hubo en otro tiempo entre los judíos, diciendo: "Existían diferentes opiniones en la circuncisión, entre los hijos de los israelitas, contra la tribu de Judá y contra el Cristo, a saber: esenios, galileos, hemerobautistas, marboteos, samaratinos, saduceos y fariseos"». Sin embargo, inmediatamente antes el mismo Hegesipo hace resaltar que la oposición franca de Tibutis es el resorte que hace saltar la frágil conjunción entre diversas corrientes de cristianos judaizantes y gentiles, permitiendo asimismo el cambio semántico de corriente de ideas a herejía como una corriente de ideas condenable: «El mismo escritor nos explica los comienzos de las herejías de su tiempo en estos términos: "Y después que Santiago el Justo hubo sufrido el martirio, lo mismo que el Señor y por la misma razón, su primo Simeón, el hijo de Clopás, fue constituido obispo. Todos le habían propuesto, por ser el otro primo del Señor. Por esta causa llamaban virgen a la Iglesia, pues todavía no se había corrompido con vanas tradiciones. Mas fue Tibutis, por no haber sido él nombrado obispo, quien comenzó a corromperla, partiendo de las siete sectas que había en el pueblo, de las cuales también él formaba parte. De ellas salieron Simón -de ahí los simonianos-, Cleobio -de donde los cleobinos-, Dositeo -de donde los dositianos-, Gorteo - de donde los goratenos- y los masboteos. De estos proceden los menandrianistas, los marcianistas, los carpocratianos, los valentinianos, los basilidianos, y los saturnilianos. Cada uno de estos introdujo su propia opinión por caminos propios y diferentes"». Entre las corrientes enumeradas en primer término por el autor palestino y las noticias que proporciona se descubren -a diferencia de la línea más reciente trazada por Justino ordenada por otras instancias críticas del judaísmo históricamente más modernas y su formación filosófica medioplatónica-, una diversidad de tendencias de fácil entendimiento y diálogo, pero asimismo rasgos de un docetismo universalista refractarios ante la posición adopcionista más externa de los judeocristianos que se ven representados en las Memorias de Hegesipo, y otros de adscripción a una escatología realizada, propios de un esoterismo iniciático en posesión de rituales y con indicios del cultivo de una especulación filosófica sobre los que dan testimonios dispersos las epístolas paulinas y deuteropaulinas y posteriormente las cartas pastorales y católicas. Pero incluso un testimonio más próximo a Justino, pero anterior a él, es asimismo Ignacio de Antioquía. Ver Jesús el Naz̧areno, 285-286.

64 Ver F. García BazÁn, El gnosticismo: esencia, origen y trayectoria (Buenos Aires 2009) cap. IV, 88-92 y caps. V-VI, 93-129. 
familiaridad con noticias que circulaban en su Samaria natal, igual que sobre la corriente simoniana:

Sigue así Justino ampliando la exégesis profética del Salmo 2, 2ss:

«O entonces llamó León que ruge contra él al diablo, a quien Moisés llama serpiente, y en Job y Zacarías se le da el nombre de diablo y por Jesús es nombrado Satanás, significando que lleva este nombre compuesto, tomado de lo mismo que el diablo hacía. Porque Satán en la lengua de hebreos y sirios vale tanto como "apóstata" y nas, en hebreo, quiere decir "serpiente". De ambos nombres se compone el de Satanás. Y fue así que, apenas Jesús salió del río Jordán...se escribe en los Recuerdos de los Apóstoles que acercándosele el diablo le tentó hasta decirle: "Adórame". A lo que Cristo le contestó: "Vete atrás, Satanás, al Señor Dios tuyo adorarás y a él solo servirás" ${ }^{65}$.

Finalmente se quiere recordar la vinculación de las denominaciones mediatas del Dios inefable o nombres del Verbo, especialmente el nombre Jesús, con el poder de la pronunciación y el uso de los exorcismos, pues ellos pueden abatir la potencia de los espíritus mágicos y enderezan de este modo el designio divino caído (5) ${ }^{66}$. Todo este diseño conceptual se acompaña asimismo de la racionalización filosófica del tiempo que lo vacía de sustancia cualitativa, la que es propia de la intensidad de la expectativa según se daba en la experiencia religiosa paleocristiana ${ }^{67}$, reemplazado por la noción de una línea cronológica que discurre entre la primera y la segunda Venida y que se tiene que completar con la actividad cósmica de las semillas del Verbo. Por imperio de las circunstancias las menciones al Reino de Dios han corrido la misma suerte entre la racionalización y la tibieza política.

65 Ver Diál. 103,5, Lc 3,22 y BoBICHON, Dialogue avec Tryphon, II, 835, n. 14. La etimología basada en la separación de la palabra Satanás (el adversario) en êatah (separarse) y na' (serpiente), parece asimismo conocerla san Ireneo refiriéndose a Mt 4,10: «Su nombre lo desnudó y lo mostró tal como es: Satanás, palabra que en hebreo significa apóstata» (Adv. Haer. V, 21,2 (Harvey II, 383) y Dem. 16.

${ }_{66}$ Ver 2Apol. 5 (6), 6 (epokrísto ), asimismo C. Munier, 313. Diál. 110, 4; 111, 3 sobre potencia del nombre (BoBichon, Dialogue avec Tryphon II, 848, n.8.).

${ }^{67}$ Mt 24,1ss; 1Tes, 4,13-5,5; Apo. y 2Tes 2, 1-12. Ver F. García BAZÁn, «Tiempo cristiano y comunidad política» en Actas V Jornadas de Filosofía Medieval (Buenos Aires 2010), CD ISBN 978-987-537-102-6. 


\section{Conclusión}

Justino de Roma es el primer escritor cristiano que ha sostenido el vínculo inseparable entre la fe y la razón. En este sentido ha afirmado la naturaleza universal y única del pensamiento cristiano y le corresponde el título legítimo de primer filósofo católico. La declaración implica dos supuestos: la admisión de elementos aceptables en las enseñanzas de la gentilidad (helénica y bárbara) y el reconocimiento de anticipos cristianos en la Ley judía y los profetas (Sagradas Escrituras del A.T. y Libros proféticos). No existe ruptura entre lo antiguo y lo nuevo, sino respeto y superación. La Palabra divina incorporada, creadora y en función de Espíritu profético (en Dios y en el tiempo), es el eje que articula este gran ensamblaje reflexivo. Su captación exige la disolución como cuerpo extraño de la herejía que se opone a la potencia divina al servicio de su contrapotencia (Satanás y los démones) y la asimilación progresiva de la filosofía gentil y la fe de los judíos para su legítima madurez y el conocimiento de la identidad cristiana frente a griegos y judíos. La piedad humana manifestada en el culto y la moral son esclarecidos por la filosofía y le son complementarios, pero no interiores a ella. Por esto ser filósofo católico encierra al mismo tiempo en Justino ser el fundador de la heresiología y de una nueva apologética, que es tanto mostración de la propia identidad como mensaje misionero.

Resumen: Justino de Roma es el primer escritor cristiano que ha sostenido el vínculo inseparable entre la fe y la razón. En este sentido, ha afirmado la naturaleza universal y única del pensamiento cristiano y así, en la tesis de esta investigación, le corresponde el título legítimo de primer filósofo católico. Este artículo profundiza en la formación cultural de Justino, para luego dedicarse a evidenciar la importancia filosófica de su Apologia y cómo, finalmente, en el Diálogo con Trifón confirmará o ampliará su doctrina filosófica, teniendo ahora a los judíos como destinatarios de esta demostración.

Palabras clave: Justino, fe y razón, Apología, Diálogo con Trifón.

Abstract: Justin of Rome (Justin Martyr) is the first Christian writer who has maintained an inseparable link between faith and reason. Thus, he has affirmed the universal and unique nature of Christian thought, and therefore, in the thesis of this research, he possesses the legitimate title of the first Catholic philosopher. This article delves into Justin's cultural background, to later show the philosophical importance of his Apology, and, how, finally, in his Dialogue with Trypho, his philosophical doctrine is confirmed or broadened, with the Jewish people now as the recipients of such demonstration.

Key words: Justin, faith and reason, Apology, Dialogue with Trypho. 